\title{
Evaluating the Impact of Educational Interventions on Use of Highly Active Antiretroviral Therapy and Adherence Behavior in Indian Human Immunodeficiency Virus Positive Patients: Prospective Randomized Controlled Study
}

Radhakrishnan Rajesh ${ }^{1 *}$, Sudha Vidyasagar ${ }^{2}$, Danturulu Muralidhar Varma ${ }^{3}$, Vasudeva Guddattu ${ }^{4}$ and Ansar Hameed ${ }^{5}$

${ }^{1}$ Department of Pharmacy Practice, Manipal College of Pharmaceutical Sciences, Manipal University, Manipal 576 104, Karnataka, India ${ }^{2}$ Professor \& Head of the Department of Medicine, Kasturba Medical College, Manipal University, Manipal 576 104, Karnataka, India

${ }^{3}$ Associate Professor, Department of Medicine, Kasturba Medical College, Manipal University, Manipal 576 104, Karnataka, India

${ }^{4}$ Asst Professor, Department of Statistics, Manipal University, Manipal 576 104, Karnataka, India

${ }^{5}$ Department of Pharmacy Practice, Manipal College of Pharmaceutical Sciences, Manipal University, Manipal 576 104, Karnataka, India

\begin{abstract}
Background: In India, there is a lack of awareness and inadequate knowledge about use of Highly Active Antiretroviral Therapy (HAART) due to social stigma leading to intentional non-adherence among Human Immunodeficiency Virus (HIV) infected patients thus, Educational Intervention (EI) must be sought.
\end{abstract}

Need for the study: There is a need for an El program for HIV-infected patients for improving adherence to Antiretroviral Therapy (ART).

Aim: The aim of the study was to evaluate the impact of an EI on use of HAART and its effect on adherence behavior in Intervention Care Group (ICG) in comparison with Standard Care Group (SCG) in HIV infected patients.

Methods: A prospective, randomized, controlled study was conducted at Kasturba hospital Manipal from August 2009 to May 2012 in HIV infected patients. The baseline response for Knowledge, Attitude, Belief, and Practice (KABP) questionnaire was assessed. Block randomization was used to assign the patients to the SCG and ICG. In ICG group, patients are educated every 4 weeks for a total of 16 weeks with Patient Information Leaflet (PIL), adherence counseling and awareness to Adverse Drug Reactions (ADRs) to ART by a clinical pharmacist. In ISG group, patients are given standard care for ART treatment by a clinician. Post KABP response was documented in both groups at $16^{\text {th }}$ week and adherence rate was measured. Repeated-measures Analysis of Variance (RANOVA) was used for the comparison of pre and post total KABP responses between ICG and SCG.

Results: A total of 256 HIV positive patients were enrolled. Out of which 16 patients were excluded because they were on traditional medicines and 240 HIV-infected patients with HAART were finally included in the study, of whom 120 (89 [74.2\%] men, 31[25.8\%] women) were randomly assigned to the ICG and 120 (99 [82.5\%] men, 21[17.5\%] women) to the SCG. Pre and post KABP responses significantly increased with mean \pm standard deviation (SD) $(p<0.001)$ and greater than $95 \%$ of adherence $(p<0.001)$ was reported in ICG after El in comparison with SCG.

Conclusion: The El program on use of HAART in this study changed their intentional non-adherence behavior, negative beliefs and social stigma.

Keywords: Educational interventions; Highly active antiretroviral therapy; Adherence; HIV; Adverse drug reactions; Knowledge; Attitudes; Belief; Practice

\section{Introduction}

Currently 1,672,875 patients in India have been registered in Human Immunodeficiency Virus (HIV)/ Acquired Immunodeficiency Syndrome (AIDS) care at 358 active Antiretroviral Therapy (ART) centres as on Sept 2012 [1]. Highly Active Antiretroviral Therapy (HAART) has led to greater longevity by reducing HIV-related morbidity and mortality. HIV-infected patients treated with HAART have been known to cause short term and long term Adverse Drug Reactions (ADRs). In India, there is a lack of awareness and inadequate knowledge about use of HAART, due to lack of individual Educational Intervention (EI) leading to a greater degree of intentional or nonintentional poor adherence to ART and HIV treatment failure [2]. Unfortunately, up to $25 \%$ of HIV-infected patients discontinue their initial HAART treatment within the first eight months due to ADRs [3].

Studies have also reported that HAART side-effects, stressful life events, poor social support are associated with poor medication adherence [4,5]. Various studies indicated that to obtain optimal long term benefits the level of ART adherence needed to be over 90\% [6-8]. The high degree of success in achieving HIV-1 RNA levels below assay detection with ART varies from $60 \%$ to $90 \%$ in clinical trials [9]. Studies from primary care centers suggest that, only on average of $50 \%$ patients achieve HIV-1 RNA levels below detection limits [10,11].

*Corresponding author: Radhakrishnan Rajesh, Department of Pharmacy Practice, Manipal College of Pharmaceutical Sciences and Kasturba Medical College Hospital, Manipal University, Manipal - 576 104, Karnataka, India, Tel: +91820-2922482; Fax:+91-820-2571998; E-mail: rrajesh3775@gmail.com

Received July 01, 2013; Accepted August 22, 2013; Published August 28, 2013

Citation: Radhakrishnan Rajesh, Sudha Vidyasagar, Muralidhar Varma D, Guddattu V, Hameed A (2013) Evaluating the Impact of Educational Interventions on Use of Highly Active Antiretroviral Therapy and Adherence Behavior in Indian Human Immunodeficiency Virus Positive Patients: Prospective Randomized Controlled Study. J AIDS Clin Res 4: 231. doi: 10.4172/2155-6113.1000231

Copyright: @ 2013 Radhakrishnan Rajesh, et al. This is an open-access article distributed under the terms of the Creative Commons Attribution License, which permits unrestricted use, distribution, and reproduction in any medium, provided the original author and source are credited. 
Citation: Radhakrishnan Rajesh, Sudha Vidyasagar, Muralidhar Varma D, Guddattu V, Hameed A (2013) Evaluating the Impact of Educational Interventions on Use of Highly Active Antiretroviral Therapy and Adherence Behavior in Indian Human Immunodeficiency Virus Positive Patients: Prospective Randomized Controlled Study. J AIDS Clin Res 4: 231. doi: 10.4172/2155-6113.1000231

Page 2 of 9

Understanding of Knowledge, Attitude, Belief, and Practice (KABP) in HIV-infected patients is a pre-requisite to develop effective EI [12]. Awareness and adequate training about HAART safety is very important among HIV infected patients for early recognition of symptoms associated with ADRs to HAART and to maintain good adherence [13]. In HIV/AIDS care, HAART medication adherence has been defined as the ability of the person living with HIV/AIDS to be involved in understanding, starting, continuing, managing, and maintaining a prescribed HAART to control viral HIV replication and to improve immune function [14]. Physicians and pharmacist play a key role to develop an individual educational program for HIV infected patients in order to improve HAART adherence and effectiveness of HIV treatment, that includes information such as factors that limits adherence, patient's social support from family and friends, understanding of HIV disease, home situation, work and daily schedules. The aims of this study were to evaluate the impact of EIs on use of HAART and to evaluate its effect on HAART adherence behavior in Intervention Care Group (ICG) in comparison with Standard Care Group (SCG).

\section{Methods}

\section{Study setting}

This study was a prospective, randomized, controlled, interventional study conducted at Kasturba Hospital, Manipal from August 2009 to May 2012. The University Ethics Committee of Manipal University approved this study.

\section{Study population}

HIV-infected patients of either sex who were receiving HAART at least one month were included in the study. HIV-infected patients who were receiving HAART along with traditional medicines practiced in India like ayurveda, yoga, naturopathy, unani, siddha and homeopathy were excluded from the study.

\section{Sample size and randomization}

Sample size was calculated by using the formula $n=2\left[\frac{z_{\alpha}+z_{\beta}}{c_{d}}\right]^{2}$

Where $\mathrm{n}=$ sample size

$z_{\alpha}$ is the percentile value of standard normal distribution for type I error fixed at $5 \%$.

$z_{\beta}$ is the percentile value of standard normal distribution for $80 \%$ power

$c_{d}$ is the Cohen's $\mathrm{d}$ effect size defined as the ratio of difference in mean percentage KAPB scores between ICG and SCG groups to pooled standard deviation of the percentage change. Where percentage change in KAPB scores is defined as percentage change $=100^{\star}$ (post score-pre score)/pre score. A pilot study of 10 subjects revealed the estimate of Cohen's $d$ to be $0.36,0.45,0.39$ and 0.42 for KAPB scores. From this we had chosen Cohen d value of 0.36 for calculating sample size as it yields maximum sample size of 120 in each group. After the baseline pre-KABP responses a block, randomization within 60 blocks of random length of size 4 was used to assign the patients to receive either ICG or SCG.

\section{Study Questionnaire and Study Design}

A validated questionnaire about KABP was used [15,16] Questionnaire was translated to local language Kanada, and back translated to English to ensure consistency. A change in the order and phrasing of the questions was made after discussion with the clinicians.
Twenty five questions included knowledge towards use of ART, HIV disease and its mode of transmission, common adverse effects of ART, awareness about adherence and its importance, what needs to be done while experiencing adverse effects to ART, attitude and beliefs about ART.

\section{Assessment of the baseline Pre-KABP responses questionnaire}

HIV positive patients, who meet the inclusion criterion, were enrolled into the study. Before randomization, each of Pre-KABP questions were assessed with all enrolled patients at the baseline to explore their KABP concerning use of ART and Pre-KABP responses were documented.

\section{Educational interventions}

The ICG participated in an EI program provided by the pharmacist addressing the benefits associated with use of HAART that are currently used to treat HIV infection, while the SCG received usual standard care. The pharmacist intervention included the provision of a three educational components consisting of provision of Patient Information Leaflets (PIL) on antiretroviral drugs, ART related counseling and awareness of ADRs to ART by using a validated pictograms [17]. For illiterate patients under ICG, education was provided in the presence of a patient representative or a literate family member as agreed by the patient. During the follow-up visits, the same patient representative/ literate family member accompanied the study patient. The intervention visits was conducted every 4 weeks for a period of 16 weeks of follow-up.

\section{Patient information leaflet (PIL)}

Validated PIL on antiretroviral drugs at our own centre was used. Information included in the PIL was about the HIV following facts:

1. That medicine does not cure HIV infection or AIDS.

2. HIV medicines must be taken in combination with other HIV medicines.

3. HIV medicines do not eliminate the risk of passing HIV to others.

4. HIV treatments may be different for each person.

5. Not all HIV medicines are right for all people.

6. The patient must consult their doctor if they have any questions about their treatment.

All enrolled patients under ICG received PIL during their outpatient visit to hospital and at the time of EI according to their prescribed ART regimen either in English or Kannada or Malayam.

\section{ART related adherence counseling \& awareness of ADRs}

During the educational program, patients under ICG were provided with ART related adherence counseling \& awareness to ADRs to ART under privacy. The counseling on antiretroviral drugs usage, awareness about adherence and its importance and safety aspects of ART was explained by using visual aids. Validated pictograms of ADRs to ART was also used as a counseling tool to improve patient's knowledge towards understanding of adverse effects of ART in both illiterate and literate patients in order to promote awareness of ADRs to ART for early identification and prevention of ADRs [17].

\section{Follow-up visits and assessment of the Post-KABP responses}

In both groups, post KABP questionnaires were re-administered at 
Citation: Radhakrishnan Rajesh, Sudha Vidyasagar, Muralidhar Varma D, Guddattu V, Hameed A (2013) Evaluating the Impact of Educational Interventions on Use of Highly Active Antiretroviral Therapy and Adherence Behavior in Indian Human Immunodeficiency Virus Positive Patients: Prospective Randomized Controlled Study. J AIDS Clin Res 4: 231. doi: 10.4172/2155-6113.1000231

Page 3 of 9

the end of 16 weeks and post-KABP responses was documented. Correct responses to pre-KABP questionnaires and post-KABP questionnaires were compared between both groups after intervention and standard care in ICG and SCG groups respectively.

\section{HAART adherence assessment}

After individual assessment of the post-KABP responses of ICG and SCG, HAART adherence was assessed by asking the patient if he/ she has missed any doses of ART and also by checking the bottle/ blister packet form both groups. Percentage of adherence from self-report was calculated by using the formula [18].

$$
\% \text { of Adherence }=\frac{\text { No.of doses patient should have taken }- \text { No of doses missed }}{\text { Noof doses patient should have taken }} \times 100
$$

\section{No of doses patient should have taken}

The estimated level of adherence was graded into three grades [less than $80 \%=12$ doses missed in a period of 30 days], $(80-95 \%=3$ to 12 doses missed in a period of 30 days) and (greater than $95 \%=<3$ doses missed in a period of 30 days $\}$ as per the National AIDS Control Organization (NACO) guidelines [19].

\section{Statistical analysis}

Frequencies with percentage were used to summarize demographic characteristics, pre and post KABP responses of SCG and ICG. Mean \pm Standard deviation was used to summarize total correct response in KABP domains. Repeated-measures Analysis of Variance (RANOVA) was used for the comparison of pre and post total KABP responses between ICG and SCG. Chi-square test was used to compare antiretroviral adherence outcomes across ICG and SCG. The patient was considered as good adherent for HAART if he or she reported $\geq 95 \%$ of the estimated level of adherence of the prescribed HAART regimen. All statistical calculations were performed using Statistical Package for Social Science (SPSS) Version 17.0. $P$-value of $<0.05$ was considered as statistically significant.

\section{Results}

During the study period, 256 HIV positive patients were enrolled among these, 16 patients were excluded because they were on traditional medicines. Only $240 \mathrm{HIV}$-infected patients with HAART were included in the study, of whom 120 (89 [74.2\%] men's, 31 [25.8\%] women's) were randomly assigned to the ICG. In SCG, 120 (99 [82.5\%] men's, 21[17.5\%] women's) were assigned. Majority of the patients in both group had baseline $\mathrm{CD} 4^{+} \mathrm{T}$-cell count $\leq 350$ cells $/ \mu$ l. About $52.6 \%$ of the patients in ICG were between the age of 21-40 years, in SCG $42.5 \%$ were between the age of $21-40$ years.

Of the 120 patients in ICG 52(43.3\%) were on tenofovir based regimen, $45(37.5 \%)$ on zidovudine based regimen, $23(19.2 \%)$ on stavudine based regimen, while the SCG 52(43.3\%) were on tenofovir based regimen, $53(44.1 \%)$ on zidovudine based regimen, $15(12.6 \%)$ on stavudine based regimen. The majority of study patients $(51.7 \%)$ under ICG were illiterate and unemployed (26.7\%) compared with the SCG. The demographic characteristics of HAART-treated patients in the SCG and ICG are shown in Table 1.

Compared with the SCG post-KABP responses, ICG post-KABP responses after EI and counseling on antiretroviral therapy was increased with correct responses for all categories of knowledge based questionnaires. Comparing correct responses to questionnaires for how HIV disease transmitted, the ICG increased from 94 at baseline pre-

\begin{tabular}{|c|c|c|}
\hline Characteristic & $\begin{array}{c}\text { Standard Care } \\
\text { Group } \\
\mathrm{n}=120(\%)\end{array}$ & $\begin{array}{c}\text { Intervention Care } \\
\text { Group } \\
n=120(\%)\end{array}$ \\
\hline \multicolumn{3}{|l|}{ Sex } \\
\hline Male & 99(82.5) & $89(74.2)$ \\
\hline Female & $21(17.5)$ & $31(25.8)$ \\
\hline \multicolumn{3}{|l|}{ CD4+ T-cell count (cells/ $/$ l) } \\
\hline$\leq 350$ & $114(95)$ & $113(94.1)$ \\
\hline $350-500$ & $4(3.3)$ & $4(3.3)$ \\
\hline$>500$ & $2(1.7)$ & $3(2.6)$ \\
\hline \multicolumn{3}{|l|}{ Age (years) } \\
\hline $21-40$ & $51(42.5)$ & $63(52.6)$ \\
\hline $41-60$ & $67(55.8)$ & $52(43.3)$ \\
\hline$>60$ & $2(1.7)$ & $5(4.1)$ \\
\hline \multicolumn{3}{|l|}{ ART regimen } \\
\hline Tenofovir + Emtricitabine+ Efavirenz & $52(43.3)$ & $52(43.3)$ \\
\hline Zidovudine + Lamivudine+Nevirapine & $53(44.1)$ & $45(37.5)$ \\
\hline Stavudine + Lamivudine+Nevirapine & $15(12.6)$ & $23(19.2)$ \\
\hline \multicolumn{3}{|l|}{ Education status } \\
\hline Literate & $71(59.1)$ & $58(48.3)$ \\
\hline Illeterate & $49(40.9)$ & $62(51.7)$ \\
\hline \multicolumn{3}{|l|}{ Employment status } \\
\hline Employed & $94(78.3)$ & $88(73.3)$ \\
\hline Unemployed & $26(21.7)$ & $32(26.7)$ \\
\hline \multicolumn{3}{|l|}{ Duration of use of antiretroviral therapy } \\
\hline Less than two years & $113(94.1)$ & 109(90.9) \\
\hline Greater than two years & $7(5.9)$ & $11(9.1)$ \\
\hline
\end{tabular}

Table 1: Demographic characteristic of patients in standard care group and Intervention care group.

KABP responses to 120 in the post-KABP responses, while the SCG increased from 84 to 104 , respectively. Overall intervention was also associated with an increase in the percentage of correct responses to all knowledge based questionnaires of post-KABP responses between SCG and ICG as summarized in Table 2.

When the patients were asked about attitude to be taken while experiencing an adverse effect to antiretroviral therapy, post-KABP responses in ICG $120(100 \%)$ reported that they will contact physician immediately, compared with the post-KABP responses in SCG118 (98.3\%). Of the patients in ICG post-KABP responses, $116(96.7 \%)$ agreed that they should not miss a dose of ART compared with the post-KABP responses in SCG 93(77.5\%).

In the ICG, EI was also associated with an increase in the percentage of correct responses toward attitude of ART compared with the post-KABP responses in SCG such as 118 (98.3\%) of patients under ICG agreed that ART is life saving, compared with 91 (75.8\%) in SCG. Patient under ICG 95 (79.2) accepted that ART should not be discontinued once the symptoms of HIV disease improves compared with $49(40.8 \%)$ in SCG. In the SCG post-KABP responses, 91 (75.8\%) of the patients reported that PIL on ART is necessary to know benefit of their medications, compared to $58(48.3 \%)$ of pre-KABP responses while in the ICG pre-KABP responses $46(38.3 \%)$ of patients agreed they get benefit from PIL. The effect of the EI and the provision of PIL increased the responses of post-KABP $88(73.3 \%)$ as the patients agreed that they got knowledge on HIV medicines usage, common adverse effects of their ART and they knew what to do when they get signs and symptoms of adverse effects with ART. Frequency distributions of the 
Citation: Radhakrishnan Rajesh, Sudha Vidyasagar, Muralidhar Varma D, Guddattu V, Hameed A (2013) Evaluating the Impact of Educational Interventions on Use of Highly Active Antiretroviral Therapy and Adherence Behavior in Indian Human Immunodeficiency Virus Positive Patients: Prospective Randomized Controlled Study. J AIDS Clin Res 4: 231. doi: 10.4172/2155-6113.1000231

Page 4 of 9

\begin{tabular}{|c|c|c|c|c|c|}
\hline \multirow{2}{*}{\multicolumn{2}{|c|}{ Knowledge based questionnaires }} & \multicolumn{2}{|c|}{ Standard Care Group } & \multicolumn{2}{|c|}{ Intervention Care Group $n=120(\%)$} \\
\hline & & Pre-KABP responses & Post- KABP responses & Pre- KABP responses & Post- KABP responses \\
\hline \multirow{3}{*}{1.} & \multicolumn{5}{|c|}{ Do you know how HIV disease is transmitted? } \\
\hline & Yes* $^{*}$ & $84(70)$ & 104(86.7) & $94(78.3)$ & $120(100)$ \\
\hline & No & $36(30)$ & $16(13.3)$ & $26(21.7)$ & \\
\hline \multirow{5}{*}{2.} & \multicolumn{5}{|c|}{ How many medications a normal antiretroviral therapy has? } \\
\hline & One & 22(18.3) & $25(20.8)$ & $27(22.5)$ & $4(3.3)$ \\
\hline & Two & $32(26.7)$ & $55(45.9)$ & $26(21.7)$ & $42(35)$ \\
\hline & More than two* & $12(10)$ & $16(13.3)$ & $7(5.8)$ & $70(58.4)$ \\
\hline & Don't know & $54(45)$ & $24(20)$ & $60(50)$ & $4(3.3)$ \\
\hline \multirow{4}{*}{3.} & \multicolumn{5}{|c|}{ Are you aware of the duration of antiretroviral therapy? } \\
\hline & Yes $^{*}$ & $59(49.2)$ & $97(80.8)$ & $61(50.8)$ & $118(98.3)$ \\
\hline & No & $18(15)$ & $8(6.7)$ & $25(20.8)$ & $2(1.7)$ \\
\hline & Don't know & $43(35.8)$ & $15(12.5)$ & $34(28.4)$ & \\
\hline \multirow{4}{*}{4.} & \multicolumn{5}{|l|}{ Is your HIV disease contagious? } \\
\hline & Yes & $10(8.3)$ & $5(4.2)$ & $3(2.5)$ & $3(2.9)$ \\
\hline & $\mathrm{No}^{*}$ & $91(75.8)$ & $110(91.6)$ & $90(75)$ & $115(96)$ \\
\hline & Don't know & 19(15.9) & $5(4.2)$ & $27(22.5)$ & $2(1.1)$ \\
\hline \multirow{6}{*}{5.} & \multicolumn{5}{|c|}{ What are the common symptoms of HIV disease? } \\
\hline & Weight loss* & $55(45.9)$ & $52(43.3)$ & $41(34.2)$ & $44(36.7)$ \\
\hline & Ulcers* & $6(5)$ & $5(4.2)$ & $5(4.2)$ & $7(5.8)$ \\
\hline & Difficult breathing* & $13(10.8)$ & $10(8.3)$ & $20(16.7)$ & $7(5.8)$ \\
\hline & All of the above* & $18(15)$ & $22(18.3)$ & $16(13.3)$ & $55(45.9)$ \\
\hline & Don't know & $28(23.3)$ & $31(25.9)$ & $38(31.6)$ & $7(5.8)$ \\
\hline \multirow{6}{*}{6.} & \multicolumn{5}{|c|}{ What are the common adverse effects of antiretroviral therapy? } \\
\hline & Anemia* & $3(2.5)$ & $7(5.8)$ & $2(1.7)$ & $13(10.8)$ \\
\hline & Diarrhea* & $1(0.8)$ & $3(2.5)$ & $8(6.7)$ & $26(21.7)$ \\
\hline & Fatigue* $^{*}$ & 14(11.7) & $18(15)$ & $11(9.2)$ & $25(20.8)$ \\
\hline & All of the above* & $2(1.7)$ & $5(4.2)$ & $1(0.8)$ & $26(21.7)$ \\
\hline & Don't know & $100(83.3)$ & $87(72.5)$ & $98(81.6)$ & $30(25)$ \\
\hline \multirow{4}{*}{7.} & \multicolumn{5}{|c|}{ Is there a best treatment for your HIV disease? } \\
\hline & Yes $^{*}$ & $78(65)$ & 104(86.7) & $79(65.8)$ & $120(100)$ \\
\hline & No & $10(8.3)$ & $6(5)$ & $2(1.7)$ & \\
\hline & Don't know & $32(26.7)$ & $10(8.3)$ & $39(32.5)$ & \\
\hline \multirow{6}{*}{8.} & \multicolumn{5}{|c|}{ Do you know how long antiretroviral therapy to be continued? } \\
\hline & Long duration therapy & $32(26.7)$ & $34(28.3)$ & $35(29.2)$ & $26(21.7)$ \\
\hline & Short duration therapy & $6(5)$ & $6(5)$ & $5(4.2)$ & \\
\hline & Very short duration therapy & $1(0.8)$ & & & \\
\hline & Lifelong therapy* & $39(32.5)$ & $67(55.9)$ & $39(32.5)$ & $94(78.3)$ \\
\hline & Don't know & $42(35)$ & $13(10.8)$ & $41(34.1)$ & \\
\hline & What does antiretroviral therapy do? & & & & \\
\hline & Yes, improves immunity* & $24(20)$ & $44(36.7)$ & $11(9.2)$ & $81(67.5)$ \\
\hline 9. & No, not improves immunity & $1(0.8)$ & $2(1.7)$ & & \\
\hline & Antiretroviral therapy not always a cure & $4(3.3)$ & $71(59.1)$ & $6(5)$ & $2(1.7)$ \\
\hline & Don't know & $91(75.9)$ & $3(2.5)$ & 103(85.8) & $37(30.8)$ \\
\hline & What are the common causes that lead & n of antiretroviral thera & & & \\
\hline & Poor adherence* & 23(19.1) & $21(17.5)$ & $22(18.3)$ & $24(20)$ \\
\hline 10 & Economical burden* & $25(20.8)$ & $28(23.3)$ & 23(19.2) & $22(18.3)$ \\
\hline 10. & ADRs/ drug allergy* & $7(5.9)$ & $9(7.5)$ & $8(6.7)$ & $4(3.3)$ \\
\hline & All of the above* & $33(27.5)$ & $36(30)$ & $31(25.8)$ & $49(40.8)$ \\
\hline & Don't know & $32(26.7)$ & $26(21.7)$ & $36(30)$ & $21(17.6)$ \\
\hline & Have you been educated about the imp & retroviral therapy? & & & \\
\hline 11. & Yes $^{*}$ & $73(60.8)$ & 113(94.2) & $57(47.5)$ & 118(98.3) \\
\hline & No & $47(39.2)$ & $7(5.8)$ & $63(52.5)$ & $2(1.7)$ \\
\hline
\end{tabular}

${ }^{*}$ Correct responses

Table 2: Frequency distribution of the patients' responses to the knowledge based questionnaires. 
Citation: Radhakrishnan Rajesh, Sudha Vidyasagar, Muralidhar Varma D, Guddattu V, Hameed A (2013) Evaluating the Impact of Educational Interventions on Use of Highly Active Antiretroviral Therapy and Adherence Behavior in Indian Human Immunodeficiency Virus Positive Patients: Prospective Randomized Controlled Study. J AIDS Clin Res 4: 231. doi: 10.4172/2155-6113.1000231

Page 5 of 9

\begin{tabular}{|c|c|c|c|c|c|}
\hline \multirow{2}{*}{\multicolumn{2}{|c|}{ Attitude based questionnaires }} & \multicolumn{2}{|c|}{ Standard Care Group } & \multicolumn{2}{|c|}{ Intervention Care Group n=120 (\%) } \\
\hline & & Pre-KABP responses & Post- KABP responses & Pre- KABP responses & Post- KABP responses \\
\hline \multirow{6}{*}{12.} & \multicolumn{5}{|c|}{ In case of experiencing an adverse effect to antiretroviral therapy what needs to be done? } \\
\hline & Dose reduced & $2(1.7)$ & & $1(0.8)$ & \\
\hline & Contact physician * & 109(90.8) & 118(98.3) & 102(85) & $120(100)$ \\
\hline & Stop taking the drug & $5(4.2)$ & & $5(4.2)$ & \\
\hline & \multicolumn{5}{|l|}{ Dose tapered and stopped } \\
\hline & Don't know & $4(3.3)$ & $2(1.7)$ & $12(10)$ & \\
\hline \multirow{4}{*}{13.} & \multicolumn{5}{|c|}{ Is it all right, if you miss a dose of antiretroviral therapy? } \\
\hline & Yes, all right & $9(7.5)$ & $3(2.5)$ & $9(7.5)$ & \\
\hline & No, it should not be missed* & $61(50.8)$ & $93(77.5)$ & $60(50)$ & 116(96.7) \\
\hline & Don't know & $50(41.7)$ & $24(20)$ & $51(42.5)$ & $4(3.3)$ \\
\hline \multirow{4}{*}{14.} & \multicolumn{5}{|c|}{ Do you think antiretroviral therapy is life saving? } \\
\hline & True/yes* & $9(7.5)$ & $91(75.8)$ & $82(68.3)$ & 118(98.3) \\
\hline & False/no & $75(62.5)$ & $8(6.7)$ & $3(2.5)$ & \\
\hline & Don't know & $36(30)$ & $21(17.5)$ & $35(29.2)$ & $2(1.7)$ \\
\hline \multirow{4}{*}{15.} & \multicolumn{5}{|c|}{ Do you think Antiretroviral therapy can be discontinued once the symptoms of HIV disease Improves? } \\
\hline & True/yes & $4(3.3)$ & $3(2.5)$ & $4(3.3)$ & $2(1.7)$ \\
\hline & False/no* & $35(29.2)$ & $49(40.8)$ & $29(24.2)$ & $95(79.2)$ \\
\hline & Don't know & $81(67.5)$ & $68(56.7)$ & $87(72.5)$ & $23(19.1)$ \\
\hline \multirow{4}{*}{16.} & \multicolumn{5}{|c|}{ Do you think patient information leaflet on antiretroviral therapy is necessary for you? } \\
\hline & Yes $^{*}$ & $58(48.3)$ & $91(75.8)$ & $46(38.3)$ & $88(73.3)$ \\
\hline & No & $12(10)$ & 14(11.7) & 14(11.7) & $18(15)$ \\
\hline & Don't know & $50(41.7)$ & $15(12.5)$ & $60(50)$ & 14(11.7) \\
\hline \multirow{4}{*}{17.} & \multicolumn{5}{|c|}{ Do you think antiretroviral therapy have to be taken regularly? } \\
\hline & Yes $^{*}$ & $120(100)$ & $120(100)$ & 113(94.2) & $120(100)$ \\
\hline & No & & & & \\
\hline & Don't know & & & $7(5.8)$ & \\
\hline \multirow{4}{*}{18.} & \multicolumn{5}{|c|}{ What you do when you experience signs and symptoms of Anemia with Antiretroviral therapy? } \\
\hline & Report to doctor * & 109(90.8) & 116(96.7) & 103(85.8) & 113(94.1) \\
\hline & Stop antiretroviral therapy & $2(1.7)$ & & $5(4.2)$ & $2(1.7)$ \\
\hline & Don't know & $9(7.5)$ & $4(3.3)$ & $12(10)$ & $5(4.2)$ \\
\hline
\end{tabular}

${ }^{*}$ Correct responses

Table 3: Frequency distribution of the patients' responses to the attitude based questionnaires.

patients' responses to the attitude-based questionnaires are mentioned in Table 3.

The effect of the intervention on belief and practice was also associated with an increase in the percentage of correct responses during post-KABP analysis compared with the SCG. Frequency distribution of the patients' responses to the beliefs and practice based questionnaires are mentioned in Table 4.

Table 5 presents the results of Repeated-measures analysis of variance test of pre and post KABP between SCG and ICG. It shows that mean \pm standard deviation significantly increased in patients in the ICG while it is just increased in patients in the SCG and the difference in change of mean \pm standard deviation was statistically significant $(\mathrm{p}<0.001)$ between pre and post KABP scores in both groups.

In HAART adherence assessment, the proportion of adherent patients became significantly higher in the ICG at \{Greater than $95 \%$ of adherence $81(67.5 \%)$, [p<0.001], 80 to $95 \%$ of adherence $33(27.5 \%)$, [p $<0.001]$, less than $80 \%$ of adherence $6(5 \%),[\mathrm{p}<0.001]\}$ compared to the proportion of adherent patients in SCG at \{Greater than $95 \%$ of adherence 58(48.3\%), 80 to $95 \%$ of adherence $52(43.3 \%)$, less than
$80 \%$ of adherence $10(8.4 \%)$. Table 6 shows the details of changes in adherence behavior outcomes between SCG and ICG in a prospective, controlled study for evaluation of EIs on safe use of HAART. During the study period there were no loss to follow-up in both groups and no deaths were reported. Figure 1 shows the flow of participants through the randomized study.

\section{Discussion}

In this randomized controlled study comparing EI and usual standard care to evaluate the impact of EI on safe use of HAART and adherence outcomes in HIV-infected positive patients who received adherence counseling to ART, demonstrating the impact of this EI with greater than $95 \%$ of adherence outcomes. Studies demonstrated that HIV-infected patients who received EI had obtained significant improvement in adherence [20-24]. Our study results also show similar positive significant association of greater than $95 \%$ of adherence outcomes to HAART in ICG patients $(67.5 \%, \mathrm{p}<0.001)$ after having received EIs on adherence counseling in comparison with SCG.

Among our ICG patients, we found that impact of EI on overall 
Citation: Radhakrishnan Rajesh, Sudha Vidyasagar, Muralidhar Varma D, Guddattu V, Hameed A (2013) Evaluating the Impact of Educational Interventions on Use of Highly Active Antiretroviral Therapy and Adherence Behavior in Indian Human Immunodeficiency Virus Positive Patients: Prospective Randomized Controlled Study. J AIDS Clin Res 4: 231. doi: 10.4172/2155-6113.1000231

Page 6 of 9

\begin{tabular}{|c|c|c|c|c|c|}
\hline \multirow{2}{*}{\multicolumn{2}{|c|}{ Beliefs and practice based questionnaires }} & \multicolumn{2}{|c|}{ Standard Care Group } & \multicolumn{2}{|c|}{ Intervention Care Group n=120 (\%) } \\
\hline & & Pre-KABP responses & Post- KABP responses & Pre- KABP responses & Post- KABP responses \\
\hline \multirow{4}{*}{19.} & \multicolumn{5}{|c|}{ Do you think you can stop taking the antiretroviral therapy once you feel better? } \\
\hline & Yes it can be stopped & $5(4.2)$ & $3(2.5)$ & $3(2.5)$ & \\
\hline & No, it should be continued* & $30(25)$ & $52(43.3)$ & $36(30)$ & $95(79.2)$ \\
\hline & Don't know & $85(70.8)$ & $65(54.2)$ & $81(67.5)$ & $25(20.8)$ \\
\hline \multirow{4}{*}{20.} & \multicolumn{5}{|c|}{ Do you know how many different medications (with name) you are currently taking? } \\
\hline & Yes* & $7(5.8)$ & $17(14.1)$ & $9(7.5)$ & $17(14.2)$ \\
\hline & Remember only few* ${ }^{*}$ & $15(12.5)$ & $18(15)$ & 16(13.3) & $23(19.2)$ \\
\hline & Don't know & $98(81.7)$ & $85(70.9)$ & $95(79.2)$ & $80(66.6)$ \\
\hline \multirow{4}{*}{21.} & \multicolumn{5}{|c|}{ What do you do when you have Diarrhea? } \\
\hline & Stop eating food & $17(14.2)$ & $13(10.8)$ & $17(14.2)$ & $10(8.3)$ \\
\hline & Keep drinking fluids* & $47(39.2)$ & $57(47.5)$ & $41(34.2)$ & $87(72.5)$ \\
\hline & Don't know & $56(46.6)$ & $50(41.7)$ & $62(51.6)$ & $23(19.2)$ \\
\hline \multirow{5}{*}{22.} & \multicolumn{5}{|c|}{ What do you do when you experience nausea while taking antiretroviral therapy? } \\
\hline & Take the pill with food ${ }^{*}$ & $25(20.8)$ & $30(25)$ & 14(11.7) & $71(59.2)$ \\
\hline & Stop taking the pill & $15(12.5)$ & 10(8.3) & 12(10) & $3(2.5)$ \\
\hline & Take the pill without food & $5(4.2)$ & $5(4.2)$ & $7(5.8)$ & $8(6.7)$ \\
\hline & Don't know & $75(62.5)$ & $75(62.5)$ & $87(72.5)$ & $38(31.6)$ \\
\hline \multirow{4}{*}{23.} & \multicolumn{5}{|c|}{ Do you skip your antiretroviral medications? } \\
\hline & Yes, very often & $12(10)$ & $12(10)$ & 14(11.7) & $13(10.8)$ \\
\hline & No* & $58(48.3)$ & $56(46.7)$ & $52(43.3)$ & $53(44.2)$ \\
\hline & Sometimes & $50(41.7)$ & $52(43.3)$ & $54(45)$ & $54(45)$ \\
\hline \multirow[t]{5}{*}{24.} & \multicolumn{5}{|c|}{ What do you do if you miss your antiretroviral medications? } \\
\hline & Skip & $39(32.5)$ & $37(30.8)$ & $40(33.3)$ & $20(16.7)$ \\
\hline & Take when remember & $46(38.3)$ & $45(37.5)$ & $54(45)$ & $11(9.2)$ \\
\hline & Skip if it's time for next dose* & $33(27.5)$ & $36(30)$ & $24(20)$ & $89(74.1)$ \\
\hline & Double the next dose & $2(1.7)$ & $2(1.7)$ & $2(1.7)$ & \\
\hline \multirow[t]{3}{*}{25.} & \multicolumn{5}{|c|}{ Does anyone help you in taking your antiretroviral medications regularly? } \\
\hline & Yes & $94(78.3)$ & $96(80)$ & $90(75)$ & $90(75)$ \\
\hline & $\mathrm{No}^{*}$ & $26(21.7)$ & $24(20)$ & $30(25)$ & $30(25)$ \\
\hline
\end{tabular}

${ }^{*}$ Correct responses

Table 4: Frequency distribution of the patients' responses to the beliefs and practice based questionnaires.

\begin{tabular}{|c|c|c|c|c|}
\hline Characteristic & $\begin{array}{c}\text { Standard CareGroup } \\
\text { Mean } \pm \text { SD }\end{array}$ & $\begin{array}{c}\text { Intervention Care Group } \\
\text { Mean } \pm \text { SD }\end{array}$ & F -value \\
\hline Pre-knowledge & $5.49 \pm 2.90$ & $5.21 \pm 2.83$ & 126.03 & $p<0.001$ \\
\hline Post-knowledge & $7.32 \pm 2.24$ & $9.46 \pm 1.60$ & 49.37 & $p<0.001$ \\
\hline Pre-attitude & $4.24 \pm 1.42$ & $4.10 \pm 1.39$ & 162.71 & $p<0.001$ \\
\hline Post-attitude & $5.65 \pm 1.19$ & $6.40 \pm 0.72$ & \\
\hline Pre-practice & $2.57 \pm 1.60$ & $2.35 \pm 1.54$ & $4.39 \pm 1.65$ & \\
\hline Post-practice & $2.93 \pm 1.62$ & 4.65 & \\
\hline
\end{tabular}

$P$ - value of $<0.05$ was considered as statistically significant

Table 5: Repeated-measures analysis of variance for the comparison between standard care group and Intervention care group.

\begin{tabular}{|c|c|c|}
\hline \multirow{2}{*}{ Antiretroviral adherence outcomes } & \multicolumn{2}{|c|}{ Number of patients $\mathrm{n}=240$} \\
\cline { 2 - 3 } & Standard Care Group $\mathrm{n}=120(\%)$ & Intervention Care Group $\mathrm{n}=120(\%)$ \\
\hline Greater than $95 \%$ of adherence & $58(48.3)$ & $81(67.5)$ \\
\hline 80 to $95 \%$ of adherence & $52(43.3)$ & $33(27.5)$ \\
\hline Less than $80 \%$ of adherence & $10(8.4)$ & $6(5)$ \\
\hline
\end{tabular}

$P$ - value of $<0.05$ was considered as statistically significant

Table 6: Antiretroviral adherence outcomes between standard care group and Intervention care group

knowledge scores about mode of HIV disease transmission, symptoms of HIV disease, awareness of adverse effects of ART, information on duration of ART, number of medications present in HAART, and knowledge acquired by using PIL on ART was increased after EI in ICG patients in comparison with SCG patients. During the baseline preKABP questionnaire assessment, it was found that there was a lack of awareness of HIV disease, inadequate knowledge of ART medication instructions such as dose, frequency, indications and the name of ART, 
Citation: Radhakrishnan Rajesh, Sudha Vidyasagar, Muralidhar Varma D, Guddattu V, Hameed A (2013) Evaluating the Impact of Educational Interventions on Use of Highly Active Antiretroviral Therapy and Adherence Behavior in Indian Human Immunodeficiency Virus Positive Patients: Prospective Randomized Controlled Study. J AIDS Clin Res 4: 231. doi: 10.4172/2155-6113.1000231

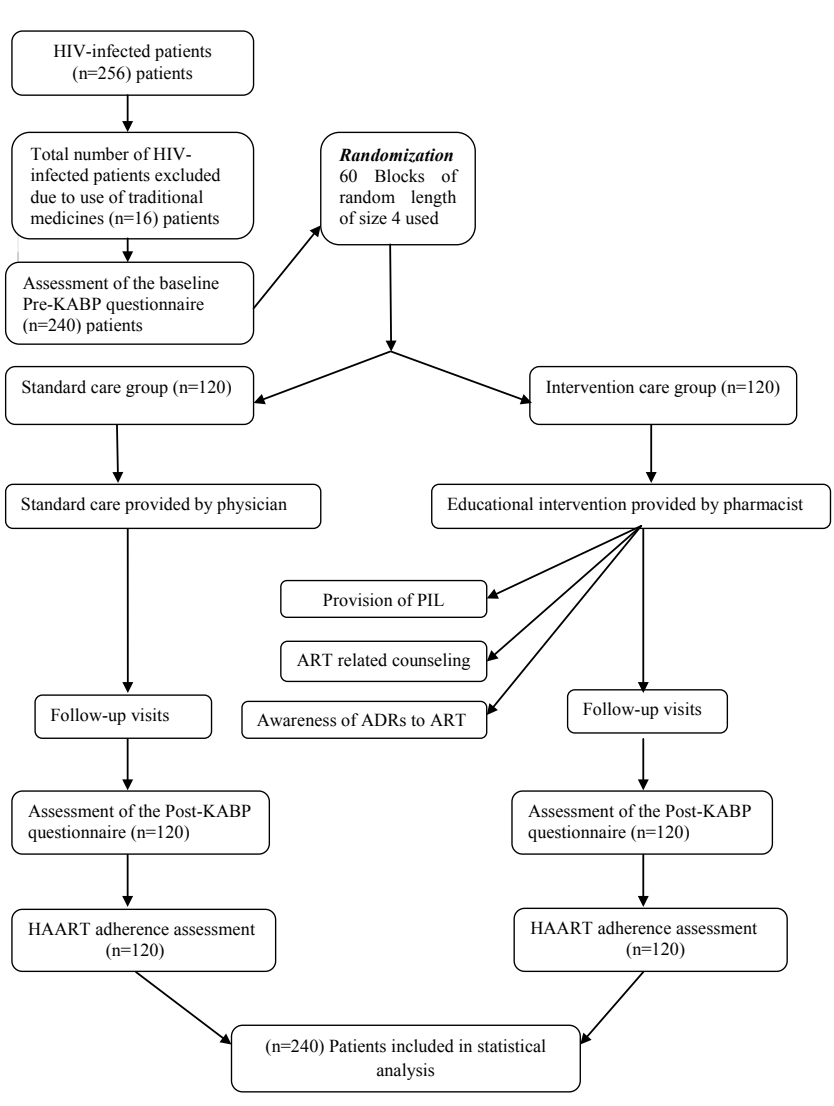

HAART - Highly Active Antiretroviral Therapy, PIL - Patient Information Leaflet KABP - Knowledge, Attitude, Belief and Practice, ART- Antiretroviral therapy

Figure 1: Flow of Participants through the randomized control study.

lack of motivation from family members and fear of social stigma among our HIV-infected patients, that made them hesitate to discuss about their ART related issues with clinicians. In our study, EI program alleviated their fears of social stigma and filled with confidence for good adherence greater than $95 \%$ in comparison with SCG patients. This finding was in accordance with Goujard et al., Weiss et al. and Nachega et al. where it was reported that EI improves adherence to antiretroviral regimens and health status [25-27].

Several studies also suggest for EI design to promote positive attitude and practice of HIV/AIDS care [28-30]. In the present study, before EI, patients who were on long term HAART had experienced adverse effects to ART, but failed to express their adverse effects to physician due to negative attitude of fear, social stigma and finally resulted in intentional non-adherence to HAART. After EI on HAART related information and counseling, these patients have shifted from negative attitude to more positive attitudes towards use of HAART and reflects in significant association between EI and positive attitude towards use of antiretroviral therapy in comparison with SCG patients.

Mini et al. study showed the impact of pharmacist provided education was found effective in improving medication adherence behavior in HIV/AIDS patients with limitation of having no control group and their study was not certain that pharmacist provided education alone improved adherence behavior [31]. Whereas our study demonstrated that EI provided by pharmacist in ICG patients reported an increase in greater than $95 \%$ of adherence $(\mathrm{p}<0.001)$ in comparison with control group of SCG patients showing that the impact of pharmacist provided
EIs on safe use of HAART were positively associated with adherence behavior to HAART in Indian HIV-infected patients.

In the ICG, EI was associated with increased queries at the time of ART related counseling, either to continue or discontinue ART once they feel better. Before counseling, patients felt that once their symptoms improve there is no need for ART medications. After educational counseling, by citing different examples patients understood that ART should be continued regularly and showed positive changes in patient's perception of continuing ART even when their symptoms subsided during their follow-up visits. These finding demonstrated that counseling could learn to change for positive attitude for adherence to HAART. Findings of positive attitude for adherence to HAART were accordance with study conducted by Chesney et al. and Wagner et al. $[32,33]$.

Our results show that, EI provided by the pharmacist also created an opportunity for HIV-infected patients to know the role of their HAART, with names of combination medications under HAART, dose and frequency. Before EI, patients were not even familiar with brand names of ART and patients' beliefs about ART were not clear because of misunderstanding of the role of HAART. After education, patients were able to retain ART related information they learned during counseling session which helped them to communicate in an easy way to clinician regarding their usage of HAART regimens, with dose and frequency during their follow-up visits. The patient's beliefs about safe use of HAART increased after our EI. These indicate that patient's learned the role of HAART than what they knew at the beginning. These are in agreement with Korb-Savoldelli et al. and Metsch et al. demonstrating that EI on medication instructions positively modify patient's beliefs which in turn can lead to a change in patient's medication adherence behavior [34,35].

During this study, ICG patients received PIL on antiretroviral drugs. The post-intervention questionnaires about the importance of PIL showed a score of $73.3 \%$, which demonstrates that provision of PIL increased the amount of information to be followed for use of ART such as, ART should be continued as prescribed by the clinician, ART should not be stopped, and should be continued, patients understood that HAART is life saving medication as detailed in the PIL. This supports Dowse et al. and Kessels et al. studies [36,37]. However, in our study, $15 \%$ of patients in ICG, after post-interventions were not happy to carry PIL. This is due to the fact that these patients had a negative beliefs that carrying the PIL on antiretroviral drugs can cause a risk of revealing their HIV status to others thereby they felt that oral information provided during EIs on ART was encouraging for them for the management of HIV disease.

In our study, awareness of adverse effects to ART in ICG patients who were prescribed on HAART regimens, individually educated and counseled about adverse effects of ART most likely to occur using validated pictograms and PIL. Overall, study patients under ICG, following the EI reported good knowledge and positive attitudes towards understanding of adverse effects of ART in both illiterate and literate patients. Awareness of adverse effects to ART among these patients impacts greatly with its association to manage early adverse effects of ART treatment, improved self-efficacy skills and HAART adherence behavior. These are in agreement with Dowse et al. and Wolf et al. studies demonstrating that awareness of ART side effects using pictograms, PIL and visual images have been shown to improve patients' knowledge, particularly in low-literate groups $[38,39]$. Our recent study showed an association between medication adherence outcomes and ADRs to HAART in Indian HIV positive patients demonstrating the 
Citation: Radhakrishnan Rajesh, Sudha Vidyasagar, Muralidhar Varma D, Guddattu V, Hameed A (2013) Evaluating the Impact of Educational Interventions on Use of Highly Active Antiretroviral Therapy and Adherence Behavior in Indian Human Immunodeficiency Virus Positive Patients: Prospective Randomized Controlled Study. J AIDS Clin Res 4: 231. doi: 10.4172/2155-6113.1000231

need for EI, to promote awareness for adverse effects of ART for the early identification of sign and symptoms of ADRs [40].

\section{Conclusion}

In this study EI showed a very good positive impact on patients' knowledge, attitude positively modified their beliefs about their ART and effectively increased antiretroviral medication adherence greater than $95 \%$. EI to ART confirm that there is large scope to promote adherence to HAART in HIV patients who have negative beliefs, social stigma and intentional non-adherence behavior.

\section{Acknowledgments}

The authors thank the staff of Departments of Medicine, Kasturba Hospital, Manipal University Manipal College of pharmaceutical sciences, Manipal University for their assistance and cooperation during the study period.

\section{References}

1. India's most comprehensive and trusted e-resource of secondary level socioeconomic information provides statistical data of India and its states.

2. Poornima P, Rajesh R, Vidyasagar S, Varma DM (2012) Assessment of hematological adverse drug reactions to antiretroviral therapy in HIV positive patients at Kasturba hospital Manipal. BMC Infect Dis 12: P55.

3. Rajesh R, Vidyasagar S, Varma DM, Mohiuddin S, Noorunnisa (2011) Evaluation of incidence of zidovudine induced anemia in Indian human immunodeficiency virus positive patients in comparison with stavudine based highly active antiretroviral therapy. Int J Risk Saf Med 23: 171-180.

4. Ammassari A, Trotta MP, Murri R, Castelli F, Narciso P, et al. (2002) Correlates and predictors of adherence to highly active antiretroviral therapy: overview of published literature. J Acquir Immune Defic Syndr 31 Suppl 3: S123-127.

5. Fogarty L, Roter D, Larson S, Burke J, Gillespie J, et al. (2002) Patient adherence to HIV medication regimens: a review of published and abstract reports. Patient Educ Couns 46: 93-108.

6. Singh N, Berman SM, Swindells S, Justis JC, Mohr JA, et al. (1999) Adherence of human immunodeficiency virus-infected patients to antiretroviral therapy. Clin Infect Dis 29: 824-830.

7. Paterson DL, Swindells S, Mohr J, Brester M, Vergis EN, et al. (2000) Adherence to protease inhibitor therapy and outcomes in patients with HIV infection. Ann Intern Med 133: 21-30

8. Bartlett JA (2002) Addressing the challenges of adherence. J Acquir Immune Defic Syndr 29 Suppl 1: S2-10.

9. Carpenter CC, Fischl MA, Hammer SM, Hirsch MS, Jacobsen DM, et al. (1997) Antiretroviral therapy for HIV infection in 1997. Updated recommendations of the International AIDS Society-USA panel. JAMA 277: 1962-1969.

10. Nieuwkerk PT, Sprangers MA, Burger DM, Hoetelmans RM, Hugen PW, et al (2001) Limited patient adherence to highly active antiretroviral therapy for HIV 1 infection in an observational cohort study. Arch Intern Med 161: 1962-1968.

11. Casado JL, Perez-Elías MJ, Antela A, Sabido R, Martí-Belda P, et al. (1998) Predictors of long-term response to protease inhibitor therapy in a cohort of HIV-infected patients. AIDS 12: F131-135.

12. Milburn K (1995) A critical review of peer education with young people with special reference to sexual health. Health Educ Res 10: 407-420.

13. Agu KA, Oparah AC, Ochei UM (2012) Knowledge and attitudes of HIV-infected patients on antiretroviral therapy regarding adverse drug reactions (ADRs) in selected hospitals in Nigeria. Perspect Clin Res 3: 95-101.

14. Jani AA (2002) Adherence to HIV treatment regimens: recommendations for best practices.

15. Nachega J, Gounder C, Doherty M (2002) Knowledge, attitude, belief and practice to HIV-infection in Sowetan adults, South Africa [ThPeC7574]. Presented at the XIV International AIDS Conference, Barcelona.

16. Medical Research Council (1998) South Africa Demographic and Health Survey 1998. Department of Health, Demographic and Health Surveys, Macro International Inc, South Africa.
17. Rajesh R, Vidyasagar S, Varma DM, Shreekant S (2012) Design and evaluation of pictograms for communicating information about adverse drug reactions to antiretroviral therapy in Indian human immunodeficiency virus positive patients. J Pharm Biomed Scien 16: 1-11.

18. Mombassa ART Project (2004) Adherence to antiretroviral therapy in adults. A Guide for trainers, Horizons population council, Kenya.

19. UNGASS (2010) Country progress report, India.

20. Simoni JM, Pearson CR, Pantalone DW, Marks G, Crepaz N (2006) Efficacy of interventions in improving highly active antiretroviral therapy adherence and HIV-1 RNA Viral load: A meta-analytic review of randomized controlled trials. J Acquir Immune Defic Syndr 43: S23-35.

21. Pradier C, Bentz L, Spire B, Tourette-Turgis C, Morin M, et al. (2003) Efficacy of an educational and counseling intervention on adherence to highly active antiretroviral therapy: French prospective controlled study. HIV Clin Trials 4 121-131.

22. Tuldra A, Fumaz CR, Ferrer MJ, Bayes R, Arno A, et al. (2000) Prospective randomized two-Arm controlled study to determine the efficacy of a specific intervention to improve long-term adherence to highly active antiretroviral therapy. J Acquir Immune Defic Syndr 25: 221-228.

23. Rathbun RC, Farmer KC, Stephens JR, Lockhart SM (2005) Impact of an adherence clinic on behavioral outcomes and virologic response in treatment of HIV infection: a prospective, randomized, controlled pilot study. Clin Ther 27: 199-209.

24. Mannheimer SB, Morse E, Matts JP, Andrews L, Child C, et al. (2006) Sustained benefit from a long-term antiretroviral adherence intervention. Results of a large randomized clinical trial. J Acquir Immune Defic Syndr 43 Suppl 1: S41-47.

25. Goujard C, Bernard N, Sohier N, Peyramond D, Lançon F, et al. (2003) Impact of a patient education program on adherence to HIV medication: a randomized clinical trial. J Acquir Immune Defic Syndr 34: 191-194.

26. Weiss L, French T, Finkelstein R, Waters M, Mukherjee R, et al. (2003) HIVrelated knowledge and adherence to HAART. AIDS Care 15: 673-679.

27. Nachega JB, Lehman DA, Hlatshwayo D, Mothopeng R, Chaisson RE, et al. (2005) HIVIAIDS and antiretroviral treatment knowledge, attitudes, beliefs, and practices in HIV-infected adults in Soweto, South Africa. J Acquir Immune Defic Syndr 38: 196-201.

28. Mini KV, Adepu R, Mothi SN, Swamy T (2010) Impact of education on knowledge attitude and practice (KAP) of HIVIAIDS patients towards their disease management-A study. Indian J pharm prac 3: 40-44.

29. Pinkerton SD, Dyatlov RV, DiFranceisco W, Benotsch EG, Smirnova TS, et al. (2003) HIVIAIDS knowledge and attitudes of STD clinic attendees in St. Petersburg, Russia. AIDS Behav 7: 221-228.

30. al-Owaish R, Moussa MA, Anwar S, al-Shoumer H, Sharma P (1999) Knowledge, attitudes, beliefs, and practices about HIVIAIDS in Kuwait. AIDS Educ Prev 11: 163-173.

31. Mini KV, Adepu R, Parthasarathi G, Mothi SN, Swamy VT (2012) Impact of pharmacist provided education on medication adherence behavior in HIVIAIDS patients treated at a non-government secondary care hospital in India. J AIDS HIV Res 4: 94-99.

32. Chesney MA, Ickovics J, Hecht FM, Sikipa G, Rabkin J (1999) Adherence: a necessity for successful HIV combination therapy. AIDS 13 Suppl A: S271-278.

33. Wagner JH, Justice AC, Chesney M, Sinclair G, Weissman S, et al. (2001) Patient- and provider-reported adherence: toward a clinically useful approach to measuring antiretroviral adherence. J Clin Epidemiol 54 Suppl 1: S91-98.

34. Korb-Savoldelli V, Gillaizeau F, Caruba T, Tauckoor A, Prognon P, et al. (2012 Information about medication in HIV-infected patients and its relation to adherence. Swiss Med Wkly 142: w13642.

35. Metsch LR, Pereyra M, del Rio C, Gardner L, Duffus WA, et al. (2004) Delivery of HIV prevention counseling by physicians at HIV medical care settings in 4 US cities. Am J Public Health 94: 1186-1192.

36. Dowse $R$ (2009) Using pictograms in a patient information leaflet to communicate antiretroviral medicines information to HIVIAIDS patients in rural South Africa. In Lagerwerf L, Boer H, Wasserman H (Eds.), Health communication in Southern Africa: Engaging with social and cultural diversity. Amsterdam/Pretoria, Rozenberg/UNISA Press: 155-75. 
Citation: Radhakrishnan Rajesh, Sudha Vidyasagar, Muralidhar Varma D, Guddattu V, Hameed A (2013) Evaluating the Impact of Educational Interventions on Use of Highly Active Antiretroviral Therapy and Adherence Behavior in Indian Human Immunodeficiency Virus Positive Patients: Prospective Randomized Controlled Study. J AIDS Clin Res 4: 231. doi: 10.4172/2155-6113.1000231

Page 9 of 9

37. Kessels RP (2003) Patients' memory for medical information. J R Soc Med 96: 219-222.

38. Dowse R, Ramela T, Barford KL, Browne SH (2010) Developing visual images for communicating information about antiretroviral side effect information to a low-literate population. Afr J AIDS Res 9: 213-224.
39. Wolf MS, Davis TC, Osborn CY, Skripkauskas S, Bennett CL, et al. (2007) Literacy, self-efficacy, and HIV medication adherence. Patient Educ Couns 65: 253-260.

40. Rajesh R, Sudha V, Varma D, Sonika S (2012) Association between medication adherence outcomes and adverse drug reactions to highly active antiretroviral therapy in Indian immunodeficiency virus-positive patients. J Young Pharm 4: 250-260. 